sleepiness and significant desaturation. An elevated serum bicarbonate level suggests the presence of obstructive sleep apnoea and should warrant measurement of daytime blood gases [9].

\section{A. BaHammam}

King Saud University, Riyadh, Saudi Arabia.

\section{STATEMENT OF INTEREST}

None declared.

\section{REFERENCES}

1 Mediano O, Barceló A, de la Peña M, Gozal D, Agustí A, Barbé F. Daytime sleepiness and polysomnographic variables in sleep apnoea patients. Eur Respir J 2007; 30: 110-113.

2 Olson AL, Zwillich C. The obesity hypoventilation syndrome. Am J Med 2005; 118: 948-956.

3 Hida W, Okabe S, Tatsumi K, et al. Nasal continuous positive airway pressure improves quality of life in obesity hypoventilation syndrome. Sleep Breath 2003; 7: 3-12.
4 Chouri-Pontarollo N, Borel JC, Tamisier R, Wuyam B, Levy P, Pépin JL. Impaired objective daytime vigilance in obesity-hypoventilation syndrome: impact of noninvasive ventilation. Chest 2007; 131: 148-155.

5 Piper AJ, Grunstein RR. Current perspectives on the obesity hypoventilation syndrome. Curr Opin Pulm Med 2007; 13: 490-496.

6 Hlavac MC, Catcheside PG, McDonald R, Eckert DJ, Windler S, McEvoy RD. Hypoxia impairs the arousal response to external resistive loading and airway occlusion during sleep. Sleep 2006; 29: 624-631.

7 Akashiba T, Akahoshi T, Kawahara S, et al. Clinical characteristics of obesity-hypoventilation syndrome in Japan: a multi-center study. Intern Med 2006; 45: 1121-1125.

8 BaHammam A, Syed S, Al-Mughairy A. Sleep-related breathing disorders in obese patients presenting with acute respiratory failure. Respir Med 2005; 99: 718-725.

9 Mokhlesi B, Tulaimat A. Obesity hypoventilation syndrome: prevalence and predictors in patients with obstructive sleep apnea. Sleep Breath 2007; 11: 203-204.

DOI: $10.1183 / 09031936.00149507$

\title{
Pulmonary embolism at home
}

\section{To the Editors:}

We wish to express serious concern about an article in a recent issue of the European Respiratory Journal, in which DAVIES et al. [1] reported on an outpatient treatment study in patients with acute pulmonary embolism (PE). In this study [1], the authors identified criteria for the safe discharge of PE patients, and these criteria were validated in a series of 157 patients with confirmed PE. At the end of acute low-molecular-weight heparin treatment, there were no in-hospital adverse events (thromboembolic recurrences, bleeding complications or deaths).

First, some variables that have been associated with prognosis in patients with PE were not considered by the clinicians responsible for patient care. Data from large observational studies of PE have confirmed systolic arterial hypotension as the most significant prognostic indicator of outcome in PE patients [2,3], but this was not an explicit exclusion criterion in the study of DAVIES et al. [1]. Conversely, deep venous

\begin{tabular}{ll} 
TABLE 1 & $\begin{array}{l}\text { Prevalence of adverse events during the first } 10 \\
\text { days after diagnosis }\end{array}$ \\
& Prevalence $\mathbf{( 9 5 \%} \mathbf{~ C l )}$ \\
\hline & \\
Death & $4.7(1.1-8.2)$ \\
Venous thromboembolism recurrence & $1.0(0.7-2.7)$ \\
Major bleeding & $2.1(0.3-4.5)$ \\
\hline
\end{tabular}

Data are presented as \%. Cl: confidence interval. thrombosis has been associated with prognosis in one study [4], but not in another [5].

Secondly, the number of adverse events in both phases of the study was extremely low as compared with any treatment trial [6] or PE registry [3]. For example, the 30-day mortality rate of the PE severity index low risk strata has ranged from 1.4 [7] to $3.1 \%[8]$.

The present authors validated this score in a prospective series of 805 consecutive patients with an objective diagnosis of acute symptomatic PE. Of these, 350 patients were excluded due to the presence of proximal deep venous thrombosis. Additional patients were excluded due to active bleeding $(n=19)$, previous PE $(n=44)$, hypotension $(n=17)$, hypoxaemia $(n=162)$, chronic obstructive pulmonary disease $(n=9)$, congestive heart failure $(n=8)$ and haemodynamic instability $(n=6)$. The prevalence of adverse events during the first 10 days of treatment in the remaining 190 (24\%) patients is shown in table 1 .

We share the idea that a highly selected group of pulmonary embolism patients could be treated at home. However, data from the literature cause us to exercise caution when interpreting the results of this study [1]. We are concerned that an excessively optimistic message diverges from the complex reality of pulmonary embolism patients.

\section{R. Otero* and D. Jiménez ${ }^{\#}$ on behalf of the Cooperative Study for the Ambulatory Treatment of Patients with Pulmonary Embolism Research Study Group}

*Pneumology Dept, Virgen del Rocío Hospital, Seville, and \#Pneumology Dept, Ramón y Cajal Hospital, Madrid, Spain. 
STATEMENT OF INTEREST

None declared.

\section{REFERENCES}

1 Davies CW, Wimperis J, Green ES, et al. Early discharge of patients with pulmonary embolism: a two-phase observational study. Eur Respir J 2007; 30: 708-714.

2 Konstantinides S, Geibel A, Olschewski M, et al. Association between thrombolytic treatment and the prognosis of hemodynamically stable patients with major pulmonary embolism: results of multicenter registry. Circulation 1997; 96: 882-888.

3 Goldhaber SZ, Visana L, De Rosa M. Acute pulmonary embolism: clinical outcomes in the International Cooperative Pulmonary Embolism Registry (ICOPER). Lancet 1999; 353: 1386-1389.

4 Wicki J, Perrier A, Perneger TV, Bounameaux H, Junod AF. Predicting adverse outcome in patients with acute pulmonary embolism: a risk score. Thromb Haemost 2000; 84: 548-552.

5 Girard P, Sanchez O, Leroyer C, et al. Deep venous thrombosis in patients with acute pulmonary embolism: prevalence, risk factors, and clinical significance. Chest 2005; 128: 1593-1600.

6 Koopman MM, Prandoni P, Piovella F, et al. Treatment of venous thrombosis with intravenous unfractionated heparin administered in the hospital as compared with subcutaneous low-molecular-weight heparin administered at home. The Tasman Study Group. N Engl J Med 1996; 334 682-687.

7 Jiménez D, Yusen RD, Otero R, et al. Prognostic models for selecting patients with acute pulmonary embolism for initial outpatient therapy. Chest 2007; 132: 24-30.

8 Aujesky D, Obrosky DS, Stone RA, et al. Derivation and validation of a prognostic model for pulmonary embolism. Am J Respir Crit Care Med 2005; 172: 1041-1046.

DOI: $10.1183 / 09031936.00143907$

\section{From the authors:}

We would like to thank R. Otero and D. Jiménez for their comments and their support for the principle of outpatient management of pulmonary embolism (PE). However, we are surprised by the tone of their letter. We believe that patients should be considered for ambulatory care for the management of PE after appropriate risk stratification. This can take many forms, such as the criteria developed and used by my group, or use of validated prognostic scores, e.g. PE severity index scores. As stated in the original paper, this score gives a prediction of 30-day mortality rather than the more useful prediction of mortality within the acute low-molecular heparin treatment phase relevant to outpatient treatment of PE, and was also unpublished at the time the study was developed or performed [1]

Systolic arterial hypertension is a prognostic marker and relates to massive or submassive PE. As such, the patients in our study would fulfil other exclusion criteria given in points 1) and 2) of the Exclusion criteria for outpatient treatment section in the Methods of the original article [1].

The number of deaths reported in the data of R. Otero and D. Jiménez suggest that the population in this database who fulfilled our study criteria were somehow different to the actual patients we prospectively sent home for outpatient treatment. This highlights the fact that caution is needed when retrospectively trying to draw conclusions from applying exclusion criteria to a database cohort compared with a prospective cohort

Patient data suggests that patients prefer to be managed in an ambulatory fashion. Therefore, we believe that with appropriate risk stratification and patient information, we should offer this service to patients who fulfil the criteria quoted in our study [1]

\section{C.W.H. Davies}

Royal Berkshire NHS Foundation Trust, Reading, UK.

\section{STATEMENT OF INTEREST}

A statement of interest for C.W.H. Davies can be found at www.erj.ersjournals.com $/ \mathrm{misc} /$ statements.shtml

\section{REFERENCES}

1 Davies CWH, Wimperis J, Green ES, et al. Early discharge of patients with pulmonary embolism: a two-phase observational study. Eur Respir J 2007; 30: 708-714.

DOl: $10.1183 / 09031936.00156407$

\section{Reference values for spirometry of the European Coal and Steel Community: time for change}

To the Editors:

Recently, an American Thoracic Society (ATS)/European Respiratory Society (ERS) Task Force suggested the need for a new Europe-wide study to derive updated reference equations for lung function [1]. Until the results of such a study become available (we have been waiting for new reference values in Europe for $\sim 25 \mathrm{yrs}$ ), the official reference 